\title{
Understanding Higher Education Institution-wide CMC Systems Implementation: A Structuration Theory Perspective towards Sustainability in Developing Countries
}

\author{
Emmanuel Dortey Tetteh, Benjamin Kwofie and Patricia Ghann \\ Koforidua Technical University, Koforidua, Ghana \\ E-mail: edtetteh@gmail.com
}

Keywords: higher education, structuration, CMC portal, adoption, implementation, institutionalization

Received: August 10, 2020

\begin{abstract}
Information Technologies have come to be accepted as the new normal in many parts of the world. Events like the outbreak of the COVID-19 have highlighted the significance of these artifacts in facilitating the continuance of or daily activities without grinding to a halt. While some educational institutions, from kindergarten all through to higher education, were actively engaged in teaching and learning, others were grappling with implementation issues. This paper takes a look at Computer-Mediated Communication (CMC) Portal implementation in HEIs within a developing country. Two Ghanaian HEIs' implementation of CMC portals is examined using Tetteh et al's CMC portal implementation framework as well as a structuration theory adapted by Orlikowski \& Robey from Giddens's work. Findings reveal an indistinct and almost absent consideration of the broader institutional goals for implementing CMC portals. It was also found that the activities involved in the adoption, implementation, and institutionalization of technology into institutional processes, are often not adequately considered, were unaligned with institutional visions, and not well understood. Strategies that can improve the utilization of CMC portal initiatives and guide implementation efforts of HEIs in Ghana are then advanced. Additionally, the study broadens our understanding of the structuration perspective on the outcomes of technology implementation in institutions providing another lens for identifying the underlying causational factors.

Povzetek: Prispevek opisuje analizo dveh implementacij CMC (Computer-Mediated Communication) portala v Gani.
\end{abstract}

\section{Introduction}

Information technology has a dual nature of an antecedent and an outcome of institutional activity. It has objective properties comprising of a set of rules and resources that are associated with mediating human action and along these lines adds to the creation, recreation, and transformation of their contexts just as it having subjective properties where it is seen as a social product of subjective human action inside a specific structural and cultural context.

There are implications for HEIs seeking to deploy CMC portals as per the institutional vision due to the duality of an IS. Institutions are bound to overlook the significance of fundamentally assessing the rules and procedures embedded in a CMC portal as against the specific requirements of the institution based on needs, opportunities, or even because of the current availability of open source and proprietary CMC portal software.

"For what reason would we like to implement this?" ought to be the most critical question every institution must pose, and the discussion through the lenses of the structuration model of IT [1] below looks at how a hastily or carefully carved response to this question holds the key to the implementation challenges of CMC portal faced by institutions.

\section{Related work}

This paper takes a look at the implementation of the Computer-Mediated Communication (CMC) Portal in HEIs within a developing country through the lens of Tetteh et al's CMC portal implementation framework as well as a structuration theory by Orlikowski \& Robey.

\subsection{CMC portal implementation framework}

The introduction of any information system (CMC portal) in HEIs brings an improvement to the old ways of teaching, learning, and the general administration within an institution. One of the frameworks by which proper implementation of such innovation can be achieved is Tetteh et als' CMC portal implementation framework which was based on Cooper \& Zmud's [2] IS implementation framework.

The framework proposes that for any successful implementation of innovation like a CMC portal, institutions must go through three (3) Phases which include seven sequential (7) stages of processes. Below is the framework of Tetteh et al as well as the explanation of the various stages.

Initiation: At this stage, Active as well as passive examining of institutional issues/ opportunities and 


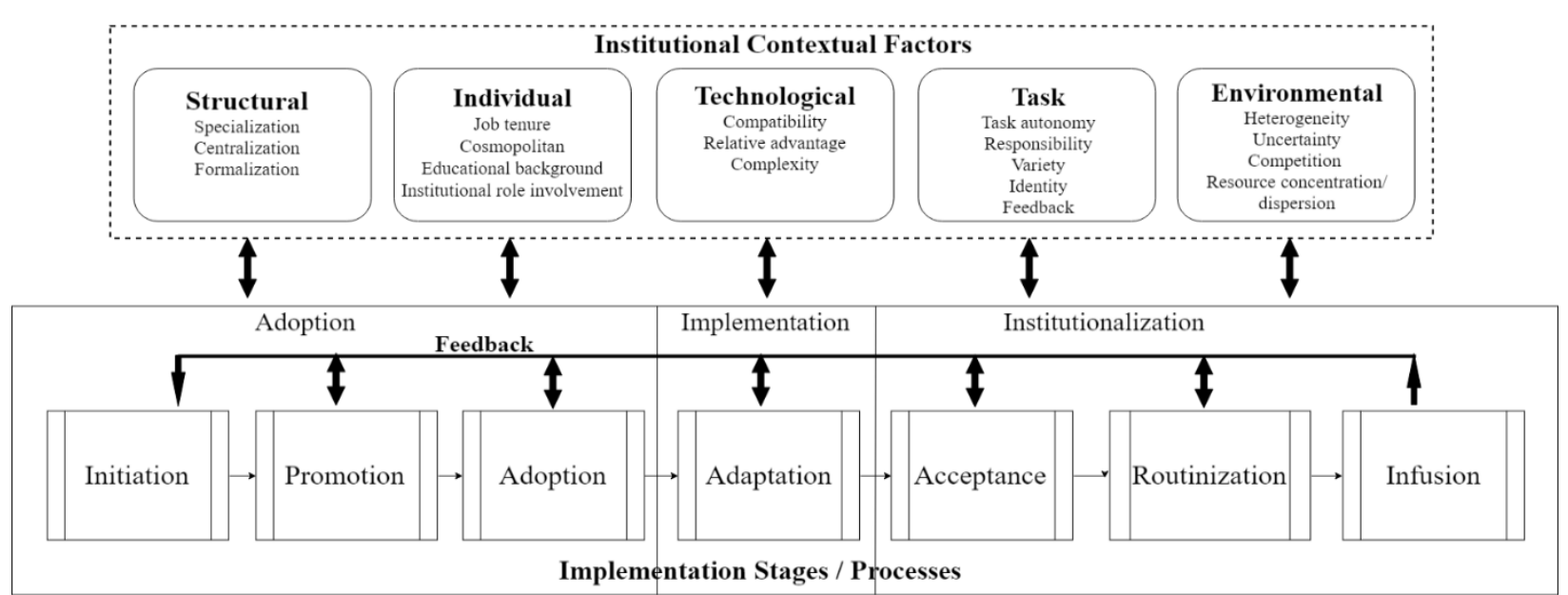

Figure 1: CMC Portal Implementation Framework

information technology solutions are birthed. Innovative ideas such as this, typically originate from either perceived institutional need (pull), perceived advantages of the technology (push), or both.

Stage Product: The identification of a match between CMC portal solutions and IT solutions in the institution.

Promotion: The identification and development of promotional strategies at all institutional levels, including faculty and departments, administrations, university resource centers, and students are carried out because successful implementation of the

CMC portal requires the promotion of the system among stakeholders.

Stage Product: The drive, cooperation, and enthusiasm of stakeholders that will facilitate the adoption of the CMC portal.

Adoption: Prudent and political talks ensue to get institutional support for CMC portal implementation.

Stage Product: A decision as to which type of CMC portal system to adapt based on some institutional specifications is carried out.

Adaptation: The development of the CMC portal system is carried out, configured to suit the requirements of the institution as well as maintained. Development of revised institutional processes are done as well as the training of stakeholders in the utilization of the new system and its new processes in the institution is also done.

Stage Product: The CMC portal system which may be proprietary or Open-source type is developed from scratch and is available for utilization in the institution.

Acceptance: Members of the institution are induced to commit to the utilization of the CMC portal system.

Stage Product: The CMC portal system is employed in the institutional activities.

Routinization: The utilization of the CMC portal as an ordinary activity by integrating with institutional processes and practices is encouraged.

Stage Product: Accustomed institutional processes and practices relating to the general administration of the institution are embedded with the CMC portal system practices.

Infusion: The integrated manner and the comprehensive utilization of the CMC portal system to help the work of higher-level areas within the institution brings about improved institutional effectiveness.

Stage Product: The CMC portal system is utilized by all users within the institution to its fullest potential.

\subsection{Structuration theory}

Information technology is placed within the structuration process which was outlined through a framework by Orlikowski and Robey [1] highlighting the importance of technology. The framework shows a system that is already in a structuration process through the modalities of interpretation, resources, and norms and an information technology added to it as though it's simply being developed.

Orlikowski \& Robey [1] argued that though Giddens' structuration theory has been used to study and analyze organizational processes, its influence in information technology studies is restricted.

The introduction of technology would mean that the technological object would have an influence on the social system, and thereby would be influenced by people who use the system. there was an assertion by Orlikowski and Robey [1] to the fact that the duality of information technology is constituted in its nature as a social product of the subjective human action within specific structural and cultural contexts, and its essential role as an objective set of rules and resources involved in mediating (facilitating and constraining) human action and hence contributing to the creation, recreation, and transforming these contexts.

They also thought of information technology as a deployment within an organization to accomplish some tasks focusing on organizationally sanctioned development and the use of technology. 


\section{Research approach}

The qualitative case study design and a variety of research approaches including the CMC portal implementation framework and a structuration perspective discussion were used to achieve the objectives of the research. The first step was the transcribing and examination of the data. The subsequent step included the critical study of the transcripts utilizing the CMC Portal implementation conceptual framework [3] involving three major phases and sub-phases which was to identify events, activities, and choices made by the institution concerning the CMC portal implementation.

Lastly, the findings were interpreted and analyzed utilizing the CMC portal implementation framework and Orlikowski and Robey's structuration model of IT.

\section{Case description}

\subsection{Case 1: Accra Institute of Technology (AIT)}

The AIT was officially established in 2009 to offer degree programs. AIT has a strong engineering and technology focus, in addition to a strong entrepreneurial focus. AIT appears to have successfully implemented on-campus and Open University programs in different fields using the open-source LMS, Moodle. Its campus-based programs are offered in the fields of engineering, computer science, information technology, and business.

AIT operates both campus-based and online (Open University) systems at both the undergraduate and the postgraduate (graduate) levels and it is credited with pioneering Open University education in Ghana and the West Africa sub-region.

\subsection{Case 2: Koforidua Technical University (KTU)}

Koforidua Technical University over the years has produced high-level career-focused and skilled manpower to support the country's industrial growth. Koforidua Technical University was established as a Polytechnic in 1997 in the Eastern Region of Ghana. Its status changed to a Technical Universities on $1^{\text {st }}$ September 2016 in compliance with the Technical University Act 2016, (Act 922). It is an outstanding tertiary institution in the Eastern Region and one of the fastest-growing Technical Universities in Ghana with immense prospects

The University currently, can currently boast of five (5) Faculties and one Institute with about eight thousand $(8,000)$ students. The University offers thirteen (13) BTech programs, twenty (20) HND programs, and other Diploma and Certificate Courses in business, engineering, and science disciplines [4].

\section{Discussion}

\subsection{A structuration perspective of institutional CMC portal implementation}

Processes preceding the physical deployment as well as processes after the deployment and utilization of the CMC portal is extensively considered as the entire implementation process. The conceptualization of these processes can bring about three broad stages within the entire process and it includes Adoption, Implementation, and institutionalization as seen in most educational change process works of literature. A discussion of the three stages is presented in the sections below.

\subsubsection{Adoption}

This stage takes a look at how the initiation, as well as the decision to introduce the CMC portal by the institutions, occur as far as who was behind and how the thought was consequently adopted or not.

\subsubsection{Institutional initiation}

The two studied cases in this research had different initiation styles,

With case 1 , a section of the ICT team was guided in the configuration of the Open Source Moodle platform, testing, the development of courseware, for the running of the institution. The CMC portal had been set up, configured, and populated before receiving accreditation to run on-campus and Open University degree programs. Due to the vice-chancellor being a former one in another university before, and by so doing had enough information concerning the use of CMCs, he was the brains behind the use of the CMC portal for the running of the institution, as well as being actively involved in the setup, the development of the various courseware for the course web sites, to ensure that these were in readiness for use by visiting members of the NAB, staff, and students.

In the case of Case 2, the participation in a workshop for HEIs on educational technology strategy for selected higher education institutions in Canada, in January 2012, highlighted the need to infuse technology into higher education. After the workshop, a team was put together to plan for the implementation of an institutional CMC portal in partnership with the Commonwealth of Learning (COL).

During that period, an institutional ICT policy was drafted to guide the development and use of the institution's IT resources which included the utilization of Moodle as the official institutional platform for all computer-mediated communication. The policy was subsequently approved by the highest body in the institution which is the governing council.

The lecturers were involved through training for the development and delivery of online courseware. The multimedia and Moodle users who were from the ICT department and other departments were also brought onboard and trained to assist in the management and development aspects of the CMC portal which included the 
Moodle setup and configuration and courseware development.

The Students were likewise trained in the utilization of the Moodle CMC portal platform through its incorporation into their compulsory ICT course in the first year of their admission.

Other stakeholders like the external collaborators were included to offer support in the areas of technical IT and online Learning during the planning and deployment of the $\mathrm{CMC}$ portal.

\subsubsection{Institutional planning}

The introduction of a CMC portal system can only be successful when holistic planning that takes into consideration available existing resources which include infrastructure, human, and capital is carried out.

Case1 had an organized approach notwithstanding the lack of a documented plan to the implementation process which began with the installation and configuration of the Moodle CMC portal platform, the development and mounting of courseware onto the Moodle CMC portal, the application for accreditation from the NAB, recruitment of lecturers and administrators, the admission of students, as well as the development and integration of other institutional IS in line with the Moodle CMC portal system.

Case 2 likewise did not have the proof of comprehensive planning aimed at the introduction of the CMC portal in the area of the deployment of the platform, the promotion of the system, training in the use of Moodle for computer-based mid-semester examinations, and so on. Planning for the training in the administration and course development of the Moodle CMC portal was however carried out.

\subsubsection{Promotion}

Promotion of the CMC portal system will enable stakeholders to know about the institutional aim for introducing the technology and enables them to become tied up with the process. Seminars and workshops organized by both internal as well as external facilitators can be a good way aimed at promoting and showing how the system works to stakeholders and these should even be possible sometime before the CMC portal system is introduced, in this manner enabling stakeholders to clear up their worries and misconceptions well before the system is ready and put into utilization.

Case 1 had the CMC portal as the institutional learning and administration platform at its commencement as an HEI. The staff and students were required to undergo training and take an obligatory examination to indicate they understand and can utilize the platform to accomplish anticipated academic goals and by these, staff and students were sensitized to the system and its centrality to everything done in the institution.

In Case 2, promotion of the CMC portal system was undertaken by the head of ICT who saw the need to get users to become tied up with the process. The promotion of the system is still an ongoing process. Seminars and workshops, as well as training sessions, were organized for stakeholders in the utilization of the Moodle CMC portal platform. There was no visible institutional plan for the promotion of the system.

\subsubsection{Infrastructural readiness}

The provision of internet/intranet, computer laboratories, computers, is important for any meaningful engagement with the CMC portal platform because the availability and readiness of the requisite IT infrastructure are critical to the successful implementation of the system. Reliable and accessible communication networks are needed by stakeholders both on-campus and off-campus to be able to engage with the CMC portal system. The system would have to be hosted on a dedicated computer server which may be internally done or externally outsourced weighing the advantages as well as disadvantages of both before a decision is made. Other issues concerning backup for the data as well as power is also of utmost great importance since the loss of data can happen if these are not taken care of. With infrastructure, both cases had unsatisfactory levels and no immediate plan was seen to be in place to improve it.

The CMC portal system was hosted on an external dedicated server outside the jurisdiction of the institution in case 1. Case 1 had two campuses with a total of 5 labs which was connected onto the portal and also free Wi-Fi internet access points on both campuses for staff and students who want to use their computers and smart electronic devices to $\log$ onto the system.

Case 2 had a total of six (6) labs containing about 400 computers which were being used to teach the computer literacy course at all levels in the institution. All these computers at the various labs were connected onto the CMC portal using the local LAN and a Wi-Fi access point was also operational at vantage points for staff and students to utilize. A special computer laboratory was set up called the thin client lab with over 100 computers to assist in conducting mid-semester examinations. The platform has not been utilized for conducting final semester examinations at both the diploma and degree levels. Active utilization of the institution's Moodle CMC portal platform was at all levels, but in particular, the weekend school program where most of their assignments and quizzes conducted. The institution still had unsatisfactory levels in terms of infrastructure despite all these.

\subsubsection{Stakeholder involvement}

Stakeholder involvement in the implementation of such innovation is critical to its success. Lecturers, students, and some administrators who directly deal with students' issues can be described as the key stakeholders in the institutions. Other staff of the institutions who do not have a direct link with students as well as external people can be classified as the secondary stakeholders. To achieve a successful implementation, it is critical to understand the role played by each of the stakeholders, their influence, as well as where and how they are involved in the implementation and utilization of the CMC portal. 
With Case 1, the system was ready with sufficient resources for use by lecturers, administrators, and students before the recruitment of all of them because the institution's CMC portal platform had been set up, configured, and populated before receiving accreditation to run on-campus and Open University degree programs. Lecturers went for training on how to use the Moodle CMC portal application before using it. Orientation for new students is done after which they are examined to ensure their ability to use the platform and other institutional stakeholders including the administrators also utilize the system for their administrative works.

With case 2, the participation in a workshop for HEIs on educational technology strategy for selected higher education institutions in Canada, in January 2012, highlighted the need to infuse technology into the institutional processes. After the workshop, a team was put together to plan for the implementation of an institutional CMC portal. The lecturers/ facilitators were also involved through training for the development and delivery of online courseware. The Moodle people who were all from the ICT department were also brought onboard and trained to assist in the management and development aspects of the CMC portal which included the Moodle setup and configuration and courseware development. Seminars and workshops, as well as formal and informal interactions with stakeholders, were deployed to get the necessary involvement and acceptance.

\subsubsection{Information technology staff readiness}

The readiness of the ICT department/directorate is essential for a successful implementation. Most of these HEIs ICT staff's original mandate has been to acquire, set up, manage as well as maintain all the IT software and hardware within the institution but with the introduction of applications for the running and management of institutions due to current developments in ICT, many technical competencies are now required from these ICT staffs. Especially, the ability to use different programming languages as well as databases which are essential in the setup and configuration of most of these CMC portal applications. The lack of these competencies by the ICT staff will warrant employing external assistance which will surely have financial implications on the institutions.

The Moodle Open source application is lately being utilized by most HEIs and this application do require some kind of tune-up to suit the demands of the institutions, however, most of these ICT staffs do not have much of this expertise in other to carry out the modifications as seen in the cases studied.

In case 1 , the ICT staff was employed after the positions were advertised to the public. Of all the positions advertised in the ICT department, only a few people applied for the position which demanded expertise in Moodle administration which shows how there is the lack of human resource for institutions that want to embark on such system implementation. The employed ICT staff have been able to set up the CMC portal and are currently integrated with some other systems which the institution is using.

Case 2 had staff who were computer science trained and could manage most IT-related tasks but were not so familiar with the setup and configuration of the Moodle CMC portal. Given that, help was provided by the Commonwealth of Learning (COL) organization in the area of setting up to training of some of the ICT directorate staff including the director of that directorate. More expertise is still needed due to the changing phase and upgrades provided by the Moodle software.

\subsubsection{External support availability}

Any institution planning on having a successful implementation of such a system like the CMC portal will surely need the support of external person(s) or organizations if there is a lack of institutional capacity in terms of the setup and configuration needed for the smooth running of the system.

Case 1 had external support in the technical configuration stage where experienced personnel who knew the setup and configuration of the Moodle CMC portal help the internal ICT staff to set up, configure as well as help the lecturers in the course content developments. There was also support in the area of security from the external internet and system hosting service providers.

In case 2, the COL provided the support in setting up, configuration, and institutionalization of the system. They also provided training to some of the selected staff of the institution. Some of the staff attended training outside the country on the use of Moodle open-source Application as a means of providing CMC between the stakeholders of the institution. This was done because the level of expertise needed to implement such a system was not available in the institution.

Institutions that want to implement such a system as the CMC portal but don't have the requisite expertise would need external support in various stages within the implementation process in other to have a successful implementation that meets its institutional goal.

\subsubsection{Consideration of core task (teaching and learning)}

Research has shown that a lot of students who enroll in courses offered online do quit without successful completion and others who enroll on the on/off-campus type using mediums like the CMC portal mostly becomes ineffective due to the lack of presence of the lecturers and so supporting and facilitating students teaching and learning through the $\mathrm{CMC}$ portal system needs a significant level of consideration as well as a careful design. If these considerations, as well as careful design, are not done, the likelihood of resistance from the stakeholders will be high due to conflict between the CMC portal software functionalities and traditional institutional practices and processes.

In case 1, the reason for the institution's establishment was to render on-campus and Open University (oncampus/online) type of education. The Open University 
system is a collaboration between another HEI outside the country which operates the Open University type of education. On-campus students are required to access their learning materials on the portal and interact with lecturers and administrators concerning their academics. The Open University students also utilize the CMC portal system for their course materials which has been designed using pedagogical principles to have the option to learn at their own pace and at the same time attend physical classroom sessions at regular two weeks intervals on weekends.

In case 2, the COL group assisted the institution in the courseware development on the Moodle CMC portal which was initially rolled out for the weekend school students and then later expanded to cover the regular session students. Students from the regular sessions attend face-to-face lectures during the weekdays whilst accessing the portal for course materials, assignment submissions, and forum discussions as well as perform academic tasks required by the administrators. The weekend students also utilize the Moodle CMC portal system to sometimes have online classroom sessions with lecturers in the evenings when needed be and also submit assignments, sometimes have mid-semester exams, have forum discussions and also perform other tasks required by the administrators concerning their academics.

\subsubsection{Implementation (physical deployment)}

For any successful institutional CMC portal implementation, there must be a successful setup and configuration as well as a successful institutional processes re-engineering. There are two different ways by which success can be achieved with the deployment of the system, the first is to adopt some of Moodle's functionality to suit institutional requirements and the second is to adapt institutional processes to fit into the functionality of the Moodle CMC portal if there are solutions provided by the functions of the system to the challenges faced by the institution.

\subsubsection{Installation and configuration}

Getting software to perform its intended functions requires a hardware component since no software runs in isolation. Technical expertise is additionally required in other to set up, configure, and host the Moodle CMC portal software, however, when these technical staff, as well as the resources needed for a successful implementation, isn't sufficient, there will be the need for an external source to provide these two which will most likely add to the cost of implementation as well as bring about security and trust concerns.

In Case 1, the installation of the Moodle CMC portal system was carried out by the employed ICT staff in collaboration with external partners. The hosting of the software was done without any difficulties on an external server by the web host's technical staff who were not part of the institution. The institution was able to incorporate almost all of its processes into the Moodle CMC portal system through the broad functionality of the system likewise the utilization of the system from its inception.
In case 2 , the installation was carried out by the head of the ICT Directorate with support from his co-workers at the directorate. The system was hosted on one of the institution's web sub-domain with the help of some staff from the COL. Help was acquired because of the shared nature of the system with other applications on the institution sever which can adversely affect the smooth running of all the system. The Moodle CMC portal had not been fully tested to see its capacity in terms of implementing all the courses to the over 10,000 students to be able to determine the system's capacity in containing simultaneous access. A little resistance to the system could be seen in this institution which could be as a result of the imposition of the Moodle CMC portal functionalities on institutional processes without the consideration of institutional processes being adapted to the system's functionalities or the system being adapted to institutional processes.

\subsubsection{Courseware development and course site setup}

Courseware involves audiovisuals, text, graphics, and other materials deemed necessary by the institution, and so experts in these areas are needed in other to bring out materials that will be pedagogically accepted for online utilization. There are several ways by which the courseware can be developed and mounted and a decision as to which way must be taken during inception by the institution. One way to do the development is to have it done in-house by each lecturer since they are the ones teaching the students, secondly, it can be done using a specially composed group within the institution, and lastly, it can be done using outsourced developers externally or buy from a commercial developer. The choice of which way to do the development will be dependent on whether the CMC portal is being used from the inception of the institution or used after the institution has been in existence for some time. The course site setup is also dependent on how the deployment is carried out, and this can be done by the trained lecturers or it can be done using a specialized group of people or department who will assign roles to the lecturers to do modification if need be. A decision in which way the courseware development and setup must be taken and enforced before deployment.

In case 1, the development and mounting of all the courseware were done before the recruitment of lecturers and admission of students into the institution. This brought about no resistance from both students and lecturers since they were trained from inception and were mandated to comply with its utilization. The lecturers are to provide recommendations if need be to the institution on how to make the courseware better, and the students are also to assess the lecturers on the utilization of the portal at the end of every semester. These measures have helped the utilization of the portal by lecturers and students and also enhanced the Moodle CMC portal application system.

Case 2 had the initial courseware developed by the lecturers of the weekend school session in collaboration with the COL since the course materials were already 
being used in the traditional way of teaching and had some trained staff of the ICT directorate doing the mounting of the courses onto the CMC portal. All lecturers of the other sessions which include the morning and evening sessions are now required to develop their courseware for the ICT directorate to mount due to the implemented ICT policy by the institution which mandates all lecturers to utilize the portal in the delivery of teaching and learning. Different kinds of courseware materials that will make teaching and learning better were being added gradually onto the portal by the institution.

Courseware development and setup is an important aspect in a successful CMC portal implementation and so a decision as to which way to carry out these two must be done before the implementation.

\subsubsection{Support staff involvement}

To achieve the main purpose of any educational institution which is teaching and learning, various groups of staff work together to make it conceivable. The successful implementation of the CMC portal depends on the active involvement in the deployment processes of not only the lecturers and students but also the various departments like the admissions, examinations, library, students' accounts, and so on who are engaged with students' services. Neglecting such groups of staff will negatively affect the institutionalization of the system as in, the system will be seen as belonging to a particular group of people as opposed to being seen as an institutional one which leads to the resistance of the system. However, most institutions frequently don't consider these groups of people during these deployment stages, and to achieve a successful implementation, there should be the involvement of these groups of staff promptly within the deployment processes.

Case 1 had all its administrative staff who were involved in the administration of teaching and learning introduced to the system upon recruitment since almost all activities could be done utilizing the CMC portal system. The system has become vital in the day-to-day running of the institution because of the Moodle application having the capability to integrate with other systems being used in the institution.

In Case 2, the involvement of the administrative staff who were involved in the administration of teaching and learning in the deployment processes was very minimal which was a result of poor holistic planning before the commencement of the system's implementation.

By these two cases studied, it can be realized that the involvement of support staff during the deployment phase is of critical importance to have a successful CMC portal implementation in institutions. The consideration of the other ISs during this phase is also important since some of these information system's output might serve as the inputs to the CMC portal or vise-visa and if this is not done, there will be undue delays in integrating the CMC portal system into the institutional activities or processes leading to unsuccessful implementation.

\subsubsection{Stakeholders initial use}

To achieve the intended objectives for the implementation of a system like the CMC portal, initial monitoring of stakeholders' utilization of the system is essential, in other to verify if the utilization conforms to how the system is meant to be used. If utilization does not conform to its expected usage, then more intervention will be needed to get stakeholders to utilize the system in its intended manner to derive the expected objectives of the CMC portal. The type of intervention will be dependent on the strategy deployed for the roll-out of the system. In the case where it is pilot based, corrective measures can be deployed to make stakeholders utilize the system for the realization of its intended objectives whilst addressing any concerns of stakeholders inhibiting intended system utilization before total roll-out. Secondary, where a total roll-out strategy is deployed, there must be constant monitoring of utilization by stakeholders to be able to provide the needed support for any concerns preventing them from utilizing the system for its intended purpose. There must be constant online presence and response from lecturers and administrators in other to make the CMC portal's utilization by students successful, and where this is done and students still don't utilize the system as required, sections must be applied to those students involved. Below is how stakeholders utilized the CMC portal system during the initial roll-out in the two cases.

In case 1 , because the CMC portal utilization was mandatory, administrators, lecturers, and students were all trained and examined on how to use the system when they were either recruited or admitted into the institution.

With the lecturers, their initial utilization was to organize their courses with the necessary course contents uploads and activate their weekly activities which include class assignments/tests, quizzes, and forum discussions online on the system for their students. The class assignments/ test, quizzes, and forum discussions all had timelines with frequent reminders which the students had to meet. Lecturers were also to upload the student's results online for the students to have access to after every midsemester or end of semester examinations. An assessment was done by lecturers on the Couse contents uploads at every end of the semester in other for improvement to be done if need be.

On the part of the students, both on-campus, as well as the Open University students, utilized the CMC portal fully for their course content materials downloads, accessing and submission of assignments, forum discussions with their mates and lecturers, notices from both lecturers and administrators, access administrative and online library services systems which are linked with the CMC portal. Parents of students can also access information concerning their children's performance as well as other administrative services within the institution.

On the part of administrators, initial utilization was carried out by only those departments which had direct linkage with student's academics and administration as well as with the lecturers. Administrative services like the students' admissions and accounts, students' registration, 
human resource, IT support, online library and other services linked with students and lecturers were all part of the initial services rendered by the CMC portal.

In Case 2, the utilization of the CMC portal by stakeholders is not mandatory. The portal's utilization was a result of a collaboration between the institution and the COL for the weekend school programs. A group of people from the COL came to give training and support to some selected staff who included administrators and lecturers on the installation and use of the Moodle CMC portal system.

Initial utilization came in the form of the lecturers of the weekend school programs uploading some of the course contents materials online for students to download. The lecturers also uploaded assignments, organized forum discussions between student-to-student and lecturers-to-students, and sometimes conducted midsemester examinations using the system. The lecturers of the regular school session which included the morning $g$ and the evening sessions were also introduced to the CMC portal afterward. They were also involved in the uploading of course materials, forum discussions, assignment uploads even though they had regular faceto-face sessions with students every time. This was done to make the students visit the portal regularly in other to get themselves accustom to its utilization.

The students from the weekend school session were the ones who had the initial utilization of the CMC portal system in the submission of their assignments online since they were only on campus for face-to-face tutorials in a two weeks intervals. They also utilized the system for forum discussion between themselves as well as their lecturers when need be. The utilization of the portal was extended to cover the rest of the students from the other sessions who utilized the system for course materials downloads, forums, notices from the administrators and lecturers, register their courses for the semester, and sometimes have mid-semester examinations.

The administrators' initial utilization of the CMC portal system came in the form of online student registration by the students' services department, the utilization was later extended to departments like the students' accounts who were involved with payments of money from students, HR, library and ICT Directorate.

The CMC portal has been officially accepted in the institution as a system for academics as well as the general administration of the institution by the stakeholders, but its mandatory utilization by the institution is yet to be enforced.

\subsubsection{Institutionalization}

The institutionalization phase which is the Postimplementation stage within the CMC portal system implementation process is where the system's functionalities are infused into the everyday activities carried out within the institution. At the institutionalization phase, the activities performed here can only be possible after a successful installation, systems configuration as well as a readily-accessible system for utilization. The evaluation of stakeholder acceptance of the systems' initial utilization is carried out at the phase, and then the necessary steps are taken to build up its acceptance if a negative acceptance is found during the initial assessment. Steps like the incorporation of the system into all stakeholders' daily activities as well as utilization of the full functionalities of the CMC portal system including integrating other IS used in the institution with the CMC portal system thereby having a bigger enterprise resource planning system are taken. An explanation concerning the institutionalization phase of the two cases is presented below.

Case 1 is the only institution amongst the two that has been able to institutionalize the utilization of the Moodle CMC portal system. almost all activities are carried out using the system by the lecturers, students, and the administrators and the portal has been integrated with other IS including Fedena which another open-source school management software making it easy to communicate with each stakeholder by the click of a button in the institution. A lot more is still on-going in terms of upgrades of the CMC portal system in other to meet all challenges faced by both the on-campus and Open University students and staff to achieve a successful institutionalization leading to the achievement of the goals set for implementing the CMC portal.

In case 2, the institutionalization of the CMC portal is lacking despite the availability of an institutional ICT poly. Utilization of the system is seen in mostly the weekend school programs where most of the lecturers upload assignments, class forum discussions, and course materials and sometimes conduct a mid-semester examination. The regular school was only utilizing the system mostly for the uploading of the course materials, and a few of the lecturers were also utilizing the system for assignment uploads, forums, and mid-semester examinations. The only institutionalization of the CMC portal was seen in the usage of the portal for every semester students' registration and exam results uploads. To achieve institutionalization of the system within the institution, a utilization policy must be drafted and implemented since there is nothing of that sort in this institution.

\section{Summary}

From the case studies, even though time will be needed for the institutionalization of innovation like the CMC portal in a HEIs, much was to be desired in terms of clear and documented strategies aimed at having a successful institutionalization which will bring about great success in the achievement of the systems' implementation goal. Holistic planning is needed before any of such systems are introduced in any institution and when such planning does not take place, the utilization of the system will be minimal when implemented which will be as a result of stakeholders resorting to the traditional methods of teaching, learning and the general administration of students. To achieve a successful institutionalization of the CMC portal, both the implementers and stakeholders must work together considering all institutional processes and activities as against the full functionalities of the 
Moodle CMC portal system. The main objectives for the introduction of the system can only be achieved when there is a successful institutionalization of the system within the institution.

\subsection{Conclusion and future work}

To achieve the goal for the introduction of a system like the CMC portal in any HEI, holistic planning will be a vital resource. The planning should take into consideration all stakeholders' activities or processes performed in the institution which the system will have an impact on as against the system's functionalities. This will then lead to a successful CMC portal implementation within any HEI. Future research can be done aimed at identifying the underlying causational factors within information systems implementation in HEIs.

\section{References}

[1] W. J. Orlikowski and D. Robey, "Information technology and the structuring of organizations," Information Systems Research, vol. 2, no. 2, pp. 143 $169,1991$. https://doi.org/10.1287/isre.2.2.143

[2] [2] R. B. Cooper and R. W. Zmud, "Information Technology Implementation Research: A Technological Diffusion Approach," Management Science, vol. 36, no. 2, pp. 123-139, 1990. https://doi.org/10.1287/mnsc.36.2.123

[3] [3] E. D. Tetteh, Z. Qin, and B. Kwofie, "ComputerMediated Communication Portal Implementation Framework: A Higher Education Institutional Perspective," International Journal of Emerging Technologies in Learning (iJET), vol. 15, no. 03, p. 180, 2020. https://doi.org/10.3991/ijet.v15i03.11641

[4] [4] Koforidua Technical University, "History," Retrieved from https://www.ktu.edu.gh/en/aboutktu/the-university/history/. [Online]. Available: https://www.ktu.edu.gh/about-ktu/theuniversity/history. [Accessed: 04-Oct-2018]. 
